\title{
INFILTRAÇÃO DE ÁGUA NO SOLO SOB DIFERENTES USOS E MANEJO
}

Emerson Renato Romeiro ${ }^{1}$

\author{
Carolina dos Santos Batista Bonini ${ }^{2}$
}

\begin{abstract}
Alfredo Bonini Neto ${ }^{3}$
RESUMO

O cultivo do solo com culturas anuais ou perenes causam a desestruturação do mesmo. $O$ monitoramento da qualidade física do solo é importante para manter ou modificar o manejo caso esteja incorreto. As culturas anuais que necessitam de preparo a cada ciclo, desestruturam mais o solo do que as pastagens e culturas perenes. Neste sentido, o objetivo deste trabalho foi avaliar a propriedade física, taxa de infiltração de agua, para monitorar a qualidade do solo nos diferentes tipos de uso e manejo. O delineamento experimental utilizado foi inteiramente casualizados, com três tratamentos: Área de vegetação natural; Área de cultivo de cultura perene e Área de pastagem degradada; com cinco repetições. Foi avaliada a taxa de infiltração de água no solo. Os dados foram analisados estatisticamente, utilizando o teste de Tukey a $5 \%$ para comparação das médias. A taxa de infiltração de água no solo foi um bom indicador de qualidade do solo. Os resultados encontrados mostram que o manejo interfere na qualidade física do solo e o melhor tratamento foi a vegetação nativa.
\end{abstract}

PALAVRAS-CHAVE: Qualidade do solo. Matéria orgânica. Infiltração de água no solo.

\section{INFILTRATION OF WATER IN SOIL UNDER DIFFERENT USES AND MANAGEMENT}

\footnotetext{
ABSTRACT

Soil cultivation with annual or perennial crops cause the destructuring of the same. The monitoring of physical and chemical quality of the soil is important to maintain or modify the soil management, case be incorrect. Annual crops that require preparation at each cycle, destructure the soil more than pastures and perennial crops. In this sense, the objective of this work was to evaluate the physical property - rate of water infiltration to monitor soil quality in different types of management. The experimental design was completely randomized with three treatments: Area of natural vegetation; Area of perennial crop cultivation and degraded pasture area; with five repetitions. A physical property was evaluated: rate of water infiltration. Data were analyzed statistically,

${ }^{1}$ Estudante de agronomia, Unicastelo. agroemersonromeiro@gmail.com

${ }^{2}$ Engenheira Agrônoma, professora assistente doutora na UNESP campus de Dracena. carolbonini@dracena.unesp.br

${ }^{3}$ Matemático, professor assistente doutor na UNESP campus de Tupã. bonini@tupa.unesp.br
} 
using the Tukey test at $5 \%$ for comparison of means. The rate of water infiltration was a good indicator of soil quality. The results show that soil management interferes in its physical quality and the best treatment was the native vegetation.

KEY-WORDS: Soil quality. Organic matter. Water infiltration into the soil.

\section{INFILTRACIÓN DE AGUA EN EL SUELO BAJO DIFERENTES USOS Y MANEJO}

\section{RESUMEN}

El cultivo del suelo con cultivos anuales o perennes causar la degradación de la misma. La calidad física y química del suelo es importante para mantener o modificar el manejo de los casos no es correcto. Los cultivos anuales que requieren preparación para cada ciclo, rompre la estructura que es de la tierra más de los pastos y los cultivos perennes. En este sentido, el objetivo de este estudio fue evaluar la propiedade física - tasa de infiltración de agua para monitorear la calidad del suelo en diferentes tipos de gestión. El diseño experimental fue completamente al azar con tres tratamientos: Área de la vegetación natural; Área de cultivo de la zona de pastos decapitados; con 5 repeticiones., se evaluaron las propiedades físicas - tasa de infiltración de agua. Los datos se analizaron estadísticamente mediante la prueba de Tukey al 5\% para la comparación de los medios. La tasa de infiltración de agua fue un buen indicador de la calidad del suelo. Los resultados muestran que la administración interfiere con la calidad física del suelo y el mejor tratamento fu ela vegetación nativa.

PALABRAS-CLAVE: La calidad del suelo. La materia orgánica. La infiltración del agua en el suelo.

\section{INTRODUÇÃO}

$\mathrm{Na}$ avaliação dos impactos ambientais, os índices de qualidade do solo são muito utilizados e são ferramentas importantes nas funções de controle, fiscalização e monitoramento de áreas destinadas à proteção ambiental.

Existem vários modelos para avaliação da qualidade do solo (QS), conforme descrito por TÓTOLA \& CHAER (2002); entretanto, esses modelos são de complexa aplicação e enfatizam a qualidade do solo voltada para a produção, sendo sua aplicação direcionada, sobretudo para a pesquisa. Dois diferentes enfoques têm sido propostos para se estabelecerem critérios de referência: solo de área sob vegetação natural, por representar as condições ecológicas de estabilidade do ambiente; e 
parâmetros agronômicos que maximizem a produção e conservem o meio ambiente (Santana \& Bahia Filho, 2002).

Segundo ALBUQUERQUE et al. (1995), a estrutura é uma propriedade sensível ao manejo e a sua qualidade deve ser analisada segundo sua forma ou com sua estabilidade (Campos et al., 1995). O efeito do manejo sobre as propriedades físicas do solo é dependente da sua textura e mineralogia, as quais influenciam a resistência e a resiliência do solo a determinada prática agrícola (Seybold et al., 1999). Geralmente, as práticas de manejo têm maior impacto sobre as propriedades físicas de solos arenosos do que de solos argilosos que apresentam menor estruturação.

ALVES \& SUZUKI (2004) observaram que o uso de plantas de cobertura aliado à sucessão de culturas (milho e soja) sob semeadura direta melhorou as propriedades físicas do solo, como porosidade, densidade do solo e resistência mecânica à penetração de uma área degradada em recuperação com uso de adubos verdes, lodo de esgoto e pastagem.

Estudos realizados por ALVES et al. (2007) verificaram que o aumento de matéria orgânica no solo, proporciona uma melhoria nas propriedades físicas do solo como redução da densidade do solo e maior infiltração de água no solo.

Com o cultivo de adubos verdes, a proteção aumento contra o impacto da água da chuva, e a qualidade física é preservada e a qualidade química é melhorada com o aumento de matéria orgânica e nutrientes disponíveis para as plantas. Bonini \& Alves (2012) verificou que os adubos verdes influenciaram positivamente na melhoria da qualidade física de um solo degradado em recuperação.

Segundo (Richart et al., 2005) os atributos mais amplamente utilizados como indicadores de qualidade física do solo são aqueles que levam em conta a profundidade efetiva de enraizamento, a porosidade total e a distribuição e tamanho dos poros, a distribuição do tamanho das partículas, a densidade do solo, a resistência do solo à penetração das raízes, o intervalo hídrico ótimo, o índice de compressão e a estabilidade dos agregados.

Os impactos do uso e manejo na qualidade física do solo têm sido quantificados, utilizando-se diferentes propriedades físicas relacionadas com a forma e com a estabilidade estrutural do solo, tais como: compactação do solo, densidade 
do solo, resistência do solo à penetração das raízes, estrutura, porosidade total, tamanho e continuidade dos poros adsorção e absorção de nutrientes, infiltração e redistribuição de água, trocas gasosas e desenvolvimento do sistema radicular (Stone \& Silveira, 2001; Bonini \& Alves, 2012; Beutler et al., 2001; Bonini \& Alves, 2011 e Ishaq et al., 2001). Como resultado dessas modificações produzidas pelo manejo inadequado resultam em decréscimo de produção (Dauda; Samari, 2002), aumento da suscetibilidade do solo a erosão e aumento da potência necessária para o preparo do solo (Canillas; Salokhe, 2002).

Pesquisas realizadas por FIGUEREDO et al (2008) verificaram que o revolvimento do solo diminuiu o teor de matéria orgânica do solo e consequentemente, a porosidade e o armazenamento de agua, em Latossolo Vermelho sob cerrado nativo.

E Trindade et al (2012) trabalhando em Neossolo Quartzarênico, também verificaram o mesmo efeito do manejo do solo, quanto maior o revolvimento, menor a estruturação e armazenamento de agua e quando há redução na porosidade, automaticamente a densidade do solo aumenta.

Assim, o objetivo deste trabalho foi avaliar a qualidade física do solo através da taxa de infiltração de agua.

\section{MATERIAL E MÉTODOS}

O experimento foi conduzido na área experimental da Fazenda de Ensino e Pesquisa da Universidade Camilo Castelo Branco - UNICASTELO, Campus de Fernandópolis, SP (Fazenda Santa Rita), localizada entre as coordenadas 20¹6'50" latitude sul e $50^{\circ} 17^{\prime} 43^{\prime \prime}$ longitude oeste e $20^{\circ} 18^{\prime} 05^{\prime \prime}$ de latitude sul e $50^{\circ} 16^{\prime} 26^{\prime \prime}$ de longitude oeste (Figura 1).

O clima da região, de acordo com a classificação de Koppen, é subtropical úmido, Aw, com inverno seco e ameno e verão quente e chuvoso (ROLIM et al., 2007). De acordo com a EMBRAPA (2007) a região é caracterizada por um período de 6 meses do ano com déficit hídrico e temperatura média de $23,5{ }^{\circ} \mathrm{C}$ (Tabela 1 ). 
Figura 1. Localização da Fazenda Santa Rita, Fernandópolis, SP.

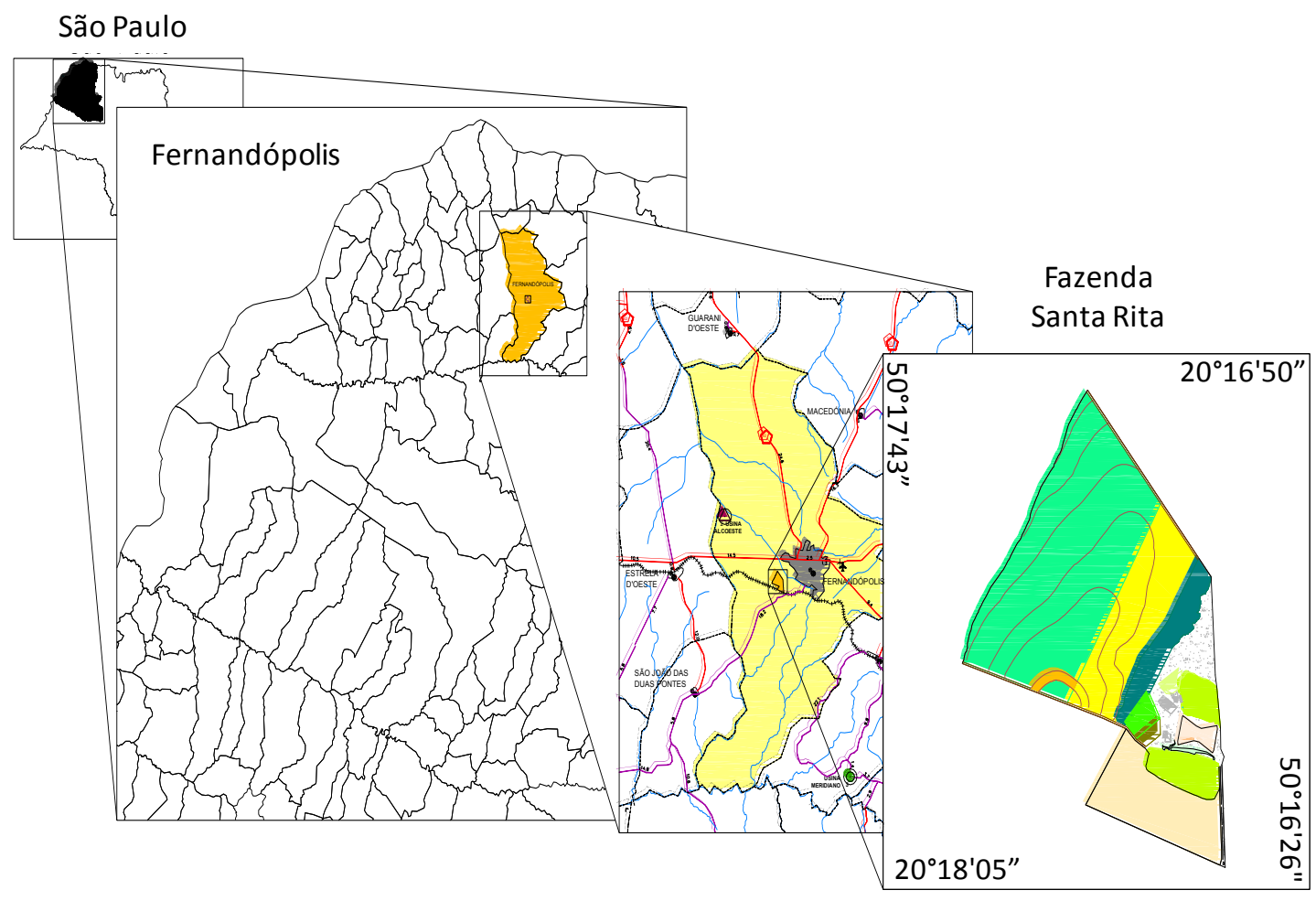

Fonte: AUTOR, 2013.

De acordo com Oliveira et al. (1999) os solos da Fazenda Santa Rita são constituídos de Argissolos Vermelhos-Amarelos eutróficos abrúpticos A moderado textura arenosa/média relevo suave ondulado e ondulado.

O delineamento experimental adotado será o inteiramente casualizados, sendo três tratamentos e cinco repetições, totalizando 25 parcelas experimentais. Sendo os tratamentos:

Tabela 1. Balanço hídrico do município de Fernandópolis, SP.

\begin{tabular}{|c|c|c|c|c|c|c|c|}
\hline \multirow{2}{*}{ Mês } & $\mathrm{T}$ & $\mathrm{P}$ & ETP & ARM & ETR & DEF & EXC \\
\cline { 2 - 8 } & $\left({ }^{\circ} \mathrm{C}\right)$ & $(\mathrm{mm})$ & $(\mathrm{mm})$ & $(\mathrm{mm})$ & $(\mathrm{mm})$ & $(\mathrm{mm})$ & $(\mathrm{mm})$ \\
\hline Jan & 25,2 & 242 & 130 & 100 & 130 & 0 & 84 \\
\hline Fev & 25,3 & 193 & 120 & 100 & 120 & 0 & 73 \\
\hline
\end{tabular}




\begin{tabular}{|c|c|c|c|c|c|c|c|}
\hline Mar & 25,0 & 131 & 124 & 100 & 124 & 0 & 7 \\
\hline Abr & 23,4 & 65 & 94 & 74 & 91 & 4 & 0 \\
\hline Mai & 21,2 & 47 & 70 & 59 & 62 & 8 & 0 \\
\hline Jun & 20,2 & 37 & 57 & 48 & 48 & 9 & 0 \\
\hline Jul & 20,1 & 13 & 58 & 31 & 30 & 27 & 0 \\
\hline Ago & 22,3 & 20 & 80 & 17 & 34 & 46 & 0 \\
\hline Set & 24,1 & 35 & 101 & 9 & 43 & 58 & 0 \\
\hline Out & 24,8 & 126 & 119 & 16 & 119 & 0 & 0 \\
\hline Nov & 24,8 & 120 & 120 & 16 & 120 & 0 & 0 \\
\hline Dez & 25,0 & 187 & 131 & 72 & 131 & 0 & 0 \\
\hline Totais & - & 1.216 & 1.205 & 642 & 1.053 & 152 & 163 \\
\hline Médias & 23,5 & - & - & - & - & - & - \\
\hline
\end{tabular}

OBS: T (temperatura média); P (precipitação); ETP (evapotranspiração potencial); ARM (armazenamento de água no solo); ETR (evapotranspiração real); DEF (deficiência); EXC (excedente). FONTE: EMBRAPA, 2007.

Área de vegetação natural (Figura 2);

Área de cultivo de cultura perene (implantada há 15 anos, espaçamento $1 \times 2$ $\mathrm{m}$, área sem manejo de adubação) (Figura 2);e

Área de pastagem degradada (3 ha) (Figura 2).

Para cada tratamento serão utilizadas amostras de solo em duplicatas para uma melhor confiabilidade dos dados.

Foi avaliada a propriedade física: Taxa de infiltração de água usando o mini infiltrômetro de disco (ZANG, 1997), conforme Figura 3.

Para a análise dos dados, foi realizada a análise de variância (teste F) e aplicou-se o teste de Tukey (5\%), para comparação das médias, utilizando o programa SISVAR (FERREIRA, 2008).

Figura 2. Vista da área experimental. 
7. Fórum Ambiental

da Alta Paulista
Volume 10, Número 7, 2014

Expansão e Produção Rural X Sustentabilidade

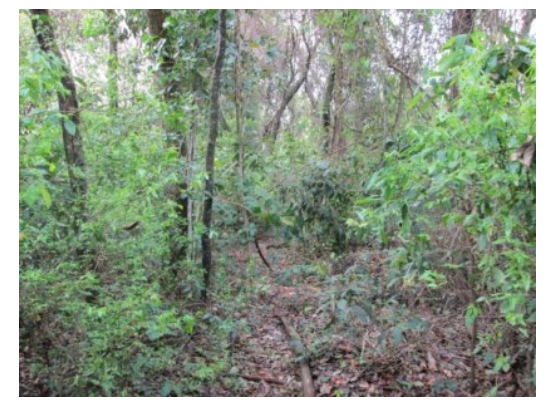

Vegetação natural

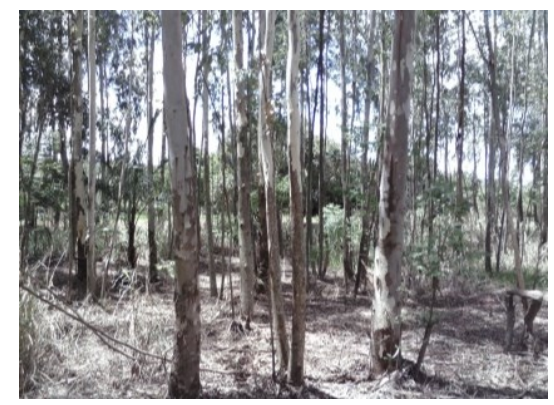

Cultura perene - Eucalipto Fonte: AUTOR, 2013.

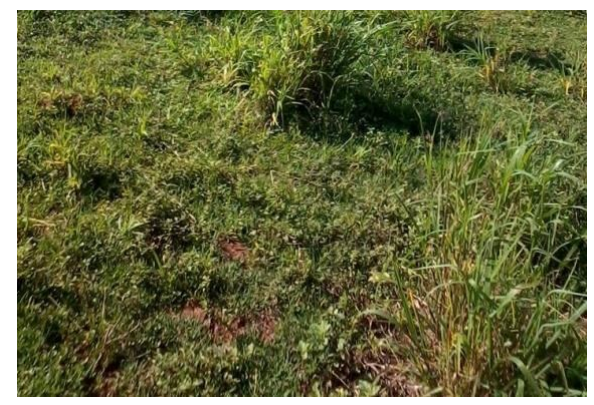

Pastagem degradada

Figura 3. Mini infiltromêtro de disco utilizado na determinação de infiltração de agua no solo.

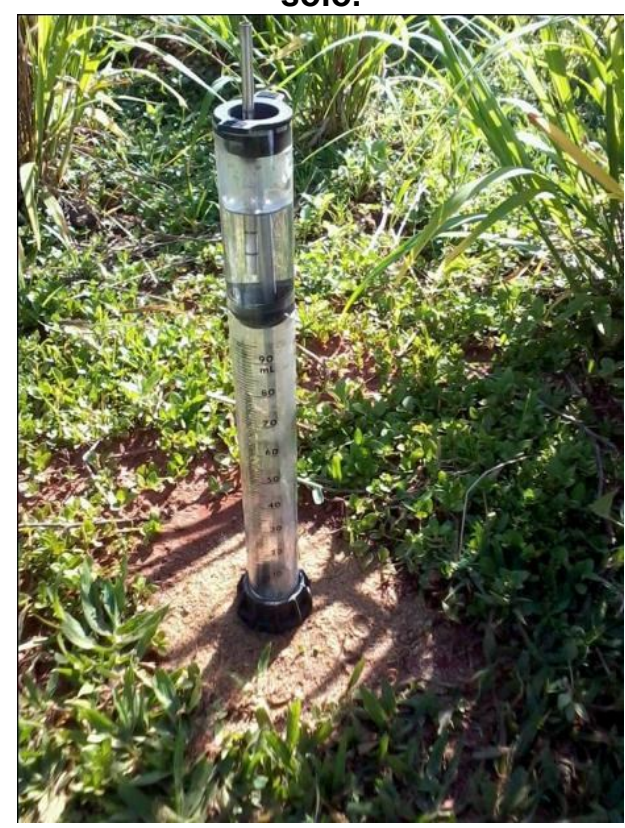

Fonte: AUTOR, 2013.

\section{RESULTADOS E DISCUSSÃO}

Os dados de infiltração de agua no solo estão apresentados na Tabela 2, e foi significativa para todos os tratamentos estudados. Em relação ao coeficiente de variação encontrado, está dentro do considerado ideal que é abaixo de $20 \%$ para analises de solo. 
Tabela 2. Teste F, DMS (5\%), CV(\%) e valores médios de infiltração de agua no solo, Resistência mecânica a penetração (RP) e umidade gravimétrica (Ug), nos diferentes usos e manejos do solo, 2013.

\begin{tabular}{|c|c|}
\hline Tratamentos & Infiltração de água no solo \\
\cline { 2 - 2 } & $\mathbf{c m ~ h}^{\mathbf{- 1}}$ \\
\hline Eucalipto & $1,98 \mathrm{~b}$ \\
\hline Pastagem & $4,17 \mathrm{a}$ \\
\hline Vegetação Nativa & $4,33 \mathrm{a}$ \\
\hline $\mathrm{F}$ & $6,487^{*}$ \\
\hline DMS - 5\% & 2,080 \\
\hline $\mathrm{CV}(\%)$ & 15,56 \\
\hline
\end{tabular}

${ }^{*}$ Significativo a $5 \%,{ }^{\text {ns }}$ não significativo. Letras iguais não diferem significativamente para o teste de Tukey (5\%). Fonte: AUTOR, 2013.

Para os tratamentos estudados, a maior infiltração foi encontrada para a vegetação nativa e a menor para o eucalipto. Esse comportamento era o esperado, pois na mata a qualidade física do solo é melhor (maior porosidade e menor densidade do solo) devido à presença de matéria orgânica e cobertura do solo pela serapilheira. Já no eucalipto as linhas e entrelinhas da cultura são desprotegidas e sobre sofre com o impacto da agua da chuva.

A pastagem que não diferiu estatisticamente da vegetação nativa também obteve um valor bom de infiltração de agua, a braquiária cobre o solo e impede a agua de desestruturar o solo e as raízes e massa seca fornecem matéria orgânica para a manutenção desse solo. Resultados semelhantes foram encontrados por BONINI (2012), ALVES et al (2007) e ALVES \& SUZUKI (2004).

Resultados semelhantes foram encontrados por Bonini (2012) que trabalhou com áreas degradadas em recuperação e verificou que na testemunha vegetação nativa a taxa de infiltração de agua no solo é maior que nos tratamentos que foram modificados pelo homem. Esses dados corroboram com os dados de infiltração encontrados neste trabalho. 
À medida que o solo está em equilíbrio com o ecossistema, a qualidade física se manifesta principalmente através da porosidade do solo que é inversamente proporcional a densidade do solo. Solo com densidade baixa possui uma maior aeração e equilíbrio solo-agua-ar.

O grande desafio ao manejar o solo é manter o aporte de matéria orgânica do solo que irá proporcionar uma melhor reestruturação do solo, maior infiltração de agua no solo e menor densidade do solo. E o revolvimento mínimo para que não haja compactação do solo.

\section{CONCLUSÃO}

Os dados da taxa de infiltração de água no solo foi um bom indicador da qualidade do solo.

$\mathrm{O}$ tratamento com vegetação nativa foi o que se destacou entre os demais. A infiltração de agua no solo foi favorecida pela maior porosidade e menor densidade do solo proporcionada pela vegetação nativa.

As análises realizadas sugerem que o manejo interfere na qualidade física do solo. Os resultados mostram que quanto maior o revolvimento do solo, menor é a infiltração de agua no solo.

\section{AGRADECIMENTOS}

À UNICASTELO - campus Fernandópolis pelo apoio e infraestrutura para realização do trabalho. 


\section{REFERÊNCIAS}

ALBUQUERQUE, J.A.; REINERT, D.J.; FIORIN, J.E.; RUEDELL, J. PETRERE, C. \& FONTINELLI, F. Rotação de culturas e sistemas de manejo do solo: efeito sobre a forma da estrutura do solo ao final de sete anos. R. Bras. Ci. Solo, 19:115-119, 1995.

ALVES, M.C.; SUZUKI, L.E.A.S. Influência de diferentes sistemas de manejo do solo na recuperação de suas propriedades físicas. Acta Sci. Agron., 26:27-34, 2004.

ALVES, M.C.; SUZUKI, L.G.A.S.; SUZUKI, L.E.A.S. Densidade do solo e infiltração de água como indicadores da qualidade física de um Latossolo Vermelho Distrófico em recuperação. Revista Brasileira de Ciência do Solo, Viçosa, v.31, n.4, p.617-625, 2007.

BEULTER, A.N.; SILVA, M.L.N.; CURI, N.; FERREIRA, M.M.; CRUZ, J.C.; PEREIRA FILHO, I.A. Resistência à penetração e permeabilidade de Latossolo Vermelho distrófico típico sob sistemas de manejo na região dos cerrados. Revista Brasileira Ciência do Solo, Viçosa, v.25, p.167$177,2001$.

BONINI, C. S. B. Restauração ecológica de um solo decapitado sob intervenção antrópica há 17 anos. 191f. Tese (Pós-Graduação em Sistemas de Produção) - Faculdade de Engenharia, Universidade Estadual Paulista “Júlio de Mesquita Filho", Ilha Solteira, 2012.

BONINI; C. S. B.; ALVES, M.C. Qualidade física de um Latossolo Vermelho em recuperação há dezessete anos. Revista Brasileira de Engenharia Agrícola e Ambiental. Campina Grande, v.16, n.4, p. 329-336, 2012.

BONINI; C. S. B.; ALVES, M.C. Recovery of soil physical properties by green manure, liming, gypsum and pasture and spontaneous native species. Revista Brasileira de Ciência do Solo, Viçosa, v.35, n.4, p.329-336, 2011.

CAMPOS, F. S. Uso de lodo de esgoto na reestruturação de Latossolo Vermelho degradado. 2006. 106 f. Dissertação (Mestrado em Agronomia) - Faculdade de Engenharia de llha Solteira, Universidade Estadual Paulista, Ilha Solteira, 2006.

CANILLAS, E. C.; SALOKHE, V. M. A decision support system for compaction assessment in agricultural soils. Soil Tillage Research, Amsterdam, v.65, n.2, p.221-230, 2002.

EMBRAPA. Banco de dados climáticos do Brasil. Brasília: Embrapa Monitoramento por Satélites, 2007. Disponível em: http://www.bdclima.cnpm.embrapa.br/. Acesso em: 23 nov. 2008.

FERREIRA, D. F.; SISVAR: um programa para análises e ensino de estatística. Revista Symposium, Lavras, v. 6, n. 1, p. 36-41, 2008.

FIGUEREDO, C.C.; RAMOS, M.L.G.; TOSTES, R. Propriedades físicas e matéria orgânica de um Latossolo Vermelho sob sistemas de manejo e Cerrado nativo. Biosci. J., v.24, n.3, p. 24-30, 2008.

ISHAQ, M.; IBRAHIM, M.; HASSAN, A.; SAEED, M.; LAL, R. Subsoil compaction effects on crop in Punjab, Pakistan: II root growth and nutrient uptake of wheat and sorghum. Soil and Tillage Research, Amsterdam, v.60, n.3/4, p.153-161, 2001

OLIVEIRA, J.B.; CAMARGO, M.N.; ROSSI, M.; CALDERANO FILHO, B. Mapa pedológico do Estado de São Paulo: legenda expandida. Campinas, Instituto Agronômico/EMBRAPA-Solos. Campinas. 1999. 64p. 
RICHART, A.; TAVARES FILHO, J.; BRITO, O. R.; LLANILLO, R. F.; FERREIRA, R. Compactação do solo: causas e efeitos Soil compacting: causes and effects. Semina: Ciências Agrárias, Londrina, v. 26, n. 3, p. 321-344, jul./set. 2005.

ROLIM, G.S.; CAMARGO, M.B.P.; LANIA, D.G.; MORAES, J.F.L. Classificação climática de Köppen e de Thornthwaite e sua aplicabilidade na determinação de zonas agroclimáticas para o estado de São Paulo. Bragantia, v.66, n.4, p.711-720, 2007.

SEYBOLD, C.A.; HERRICK, J.E. \& BREJDA, J.J. Soil resilience: a fundamental component of soil quality. Soil Sci., 164:224-234, 1999.

STONE, L.F.; SILVEIRA, P.M. Efeitos do sistema de preparo e da rotação de culturas na porosidade e densidade do solo. Revista Brasileira Ciência do Solo, Viçosa, v.25, p.395-401, 2001.

TÓTOLA, M.R. \& CHAER, G.M. Microrganismos e processos microbiológicos como indicadores da qualidade dos solos. In: ALVAREZ V, V.H.; SCHAEFER, C.E.G.R.; BARROS, N.F.; MELLO, J.W.V. \& COSTA, L.M., eds. Tópicos em ciência do solo. Viçosa, MG, Sociedade Brasileira de Ciência do Solo. 2002. v.2. p.196-276.

TRINDADE, E. F. S.; VALENTE, M.A.; MOURÃO JUNIOR, M. Propriedades físicas do solo sob diferentes sistemas de manejo da capoeira no nordeste Paraense. Revista Agrossistemas, v.4, n.1, p. 50-67, 2012.

ZANG, R. Determination of soil sorptivity and hydraulic conductivity from the disk infiltrometer. Soil Science Society of American Journal, v.61, p.1024-1030, 1997. 